\title{
CARTAS INÉDITAS DE RICARDO PALMA A DANIEL GRANADA. PARA LA HISTORIA DE LAS ACADEMIAS
}

\author{
Humberto López Morales \\ Universidad de Puerto Rico
}

I.

En 1889, en Montevideo, publica Daniel Granada su Vocabulario rioplatense razonado ${ }^{1}$; tenía entonces 43 años el jurista, nacido en Vigo, que hacía su primera incursión en el campo de la lingüística. Lo que significó -y significa- el trabajo de Granada en la fundación de la lexicografía hispanoamericana ha sido puesto de manifiesto con singular acierto por Ursula $\mathrm{Köhl}^{2}$.

1 A esta primera edición -Vocabulario rioplatense razonado (...) precedido de un juicio crítico por el Dr. Alejandro Magariños Cervantes, miembro correspondiente de la Academia Española, Montevideo: Imprenta Elzeviriana de C. Becchi y C." (...), 1889siguió la segunda «considerablemente aumentada», a la que se añade un nuevo juicio critico de D. Juan Valera, individuo de número de la Academia Española, Montevideo: Imprenta Rural, 1890. La tercera y última edición, ya póstuma, consta de dos volúmenes (I, A-D; II, E-Z) y lleva prólogo de Lauro Ayestarán y otras piezas editoriales, Montevideo: Biblioteca Artigas, Clásicos Uruguayos, vols. 25 y 26, 1957. El vocabulario fue re producido parcialmente con el título de Vocabulario rioplatense como parte del Tesoro de voces y provincialismos bispano-americanos, tomo 1 , Parte Primera. La región del Rlo de la Plata, publicado por Carlos Lentzner, Halle-Leipzig, Ehrhardt Karras, 1892. Pero su labor lingülstica no termina con el Vocabulario; le siguieron: $*$ El americanismo en los vocabularios español y portugués», BAAL, 15, 1919, págs. 496-507; el «Vocabulario paranense, o sea vocabulario de las regiones del Paraná, con noticias históricas de antiguas costumbres de sus moradores», $B A E, 7,1920$, págs. 82-85; «Terminologia indiana. Apuntamientos sobre la encomiendaw, BAE, 8, 1921, págs. 726-740; «Apuntamientos sobre lexicografía americana con especial aplicación al Río de la Plata», BAAL, 15, 1946, págs. 287-365, y sus dos valiosísimas monografías sobre terminologia hípica: «Sobre los nombres de los colores del caballo en América», BAE, 7, 1920, págs, 628-632, y «Terminología hípica espafiola e hispanoamericana. El pelo zaino en España y en América. Su carencia de uniformidad», $B A E, 8,1921$, págs. 58-63 y 187-198. Redactó además la entrada *Idioma Nacional» para el Diccionario Geográfico del Uruguay de O. Araújo, Montevideo, 1990, págs. 1-15.

2 Los inicios de la lexicografia del español del Uruguay. El 'Vocabulario Rioplatense 
Uno de los más importantes destinatarios del Vocabulario fue Ricardo Palma, a la sazón director de la Biblioteca Nacional de Lima. Para entonces Ricardo Palma tenía tras si una biografía impresionante en el mundo de la cultura, y aunque las Tradiciones, que aún seguía escribiendo, han opacado el resto de su producción, no debe olvidarse su creación poética, sus múltiples trabajos periodísticos $\mathrm{y}$ sus inquietudes lingüísticas, que arreciaron desde 1887, en que fue nombrado director de la Academia Peruana de la Lengua, que acababa de fundarse entonces ${ }^{3}$.

Palma tenía dos importantes motivos para recibir con júbilo el regalo del novel lexicógrafo: primero, sus aficiones personales, que quedan muy de manifiesto en su carta de agradecimiento, la primera de nuestra colección; segundo, porque tenía la misión de rehacer la Biblioteca Nacional, saqueada y destruida por los chilenos en 1879. En 1883 se firma el Tratado de paz entre ambos países y se le nombra director de la Biblioteca con el encargo de que llenara los anaqueles, auxiliado por la generosidad de sus amigos del extranjero, que no eran pocos. Muchisimas de las cartas que escribe por entonces el incansable corresponsal que fue Palma iban encaminadas a ese fin: se convirtió en un "bibliotecario mendigo", como él mismo se calificaba.

Cuando recibe el libro de Granada lo peor habia pasado ya ; Ricardo Palma, con un éxito sin precedentes, logra inaugurar la Biblioteca en un año escaso con 20.000 volúmenes, regalados, en sus anaqueles. Habian pasado ya casi seis años, pero seguía pidiendo.

Eso explica su carta de marzo de 1889 , en la que informa a Daniel Granada que el ejemplar dedicado de su libro lo ha cedido a la Biblioteca $\mathrm{Na-}$ cional, y le ruega, por ello, que le envíe otro para su librería personal. Palma la califica de 'modesta', y así debió ser entonces, pues el ataque chileno también deshizo su colección y varios de sus manuscritos ${ }^{4}$.

Razonado' por Daniel Granada (1889-1890). A detailed analysis of an early regional dictionary with an evaluation of its influence on later lexicographers, Tübingen, Max Nie meyer Verlag, 1986.

3 Vid. fundamentalmente las siguientes obras: Neolojismos $i$ americanismos, Lima, 1895 (52 págs.), reproducido en su libro Recuerdos de España, 2.* ed., Lima, 1899, págs. 225-300; Dos mil setecientas voces que hacen falta en el Diccionario; papeletas lexicográficas, Lima, 1903, y «De neologismos y americanismos», Union Ibero-Americana, 5, 1920, págs. 225-226, publicado póstumamente. Con relación a la obra de Palma, cf. Raúl Porras Barrenechea, Bibliografía de don Ricardo Palma, Lima, Torres Aguirre, 1952.

- Para todo lo relacionado con la biografía de Palma, cf. las siguientes obras: Luis Alberto Sánchez, Don Ricardo Palma y Lima, Lima, Torres Aguirre, 1927; Guillermo Feliú Cruz, En torno a Ricardo Palma, 2 vols., Santiago de Chile, Prensas de la Universidad de Chile, 1933; Angélica Palma, Ricardo Palma, Buenos Aires, Tor, 1933; Jorge Guillermo Leguía, Don Ricardo Palma, Lima, Compafifa de Impresiones y Publicidad, 1934; Ventura Garcia Calderón, Ricardo Palma, Paris, Desclee de Brouwer et Cie, 1938; José Miguel Oviedo, Genio y figura de Ricardo Palma, Buenos Aires, EUDEBA, 1965, y, además, los dos volúmenes colectivos, Ricardo Palma, 1833-1933, Lima, Sociedad de Amigos de Ricardo Palma, 1934, publicados en ocasión del centenario de su nacimiento. 
A partir de esta primera carta la relación epistolar entre estos dos hombres fue muy estrecha y continuada. En 1904, Daniel Granada vuelve a España, se instala en Madrid y asiste periódicamente a la Academia Española, de la que era correspondiente. Hasta la muerte de Ricardo Palma, ocurrida en octubre de 1919, no cesó la comunicación entre ambos: al principio escribía el mismo Palma; después, cuando los achaques de su salud quebrantada no se lo permitieron, le dictaba a una de sus hijas o a algún secretario.

II.

A partir de su segunda carta, de abril de 1909 , las preocupaciones por los americanismos, en particular peruanismos, que Palma quería que la Academia incorporara al $D R A E$, son una constante. El tono que las acompaña, sin embargo, es muy desigual : va desde una aparente curiosidad desinteresada, a la ironía refinada y hasta el enojo desnudo de ornamento. Todo ello, naturalmente, tiene sus antecedentes.

En 1892 Palma logra hacer realidad su sueño dorado: visitar España. Había estado antes en París y en Londres, pero España seguía siendo para él una meta dorada. El Gobierno peruano lo envía como su representante para que asistiera a varios congresos y reuniones, convocados con ocasión de celebrarse el IV Centenario del descubrimiento de América. Palma vivió en Madrid varios meses, época en la que frecuentó mucho la Academia y trabó relaciones de afecto y amistad con los que entonces ocupaban los sillones del palacete de la calle de Felipe IV.

En aquella ocasión, Palma llevó a la Corporación madrileña una lista de 350 americanismos para que fueran considerados por la Academia; tenía la ilusión de que muchos de ellos fueran aceptados y figuraran pronto en las páginas del Diccionario, pero no fue así. Durante aquella visita ninguno de ellos fue aceptado y el Director de la Academia Peruana se volvió a su país con una amarga desilusión. Es verdad que pocos años más tarde, al menos la mitad de ellos, fue recibida con entusiasmo y que con posterioridad, muchos otros también se fueron incorporando. Sin embargo, Palma se quedó con aquella primera impresión durante muchos años: de ahí su irritación y, en ocasiones, su desmesura. Un estudio sobre sus trabajos lexicográficos más importantes -Neologismos y americanismos (1895) y Dos mil setecientas voces que hacen falta en el Diccionario; Papeletas lexicográficas (1903)están a la espera de estudio cuidadoso, con respecto a su incorporación definitiva al $D R A E$. 
III.

En esta colección de cartas el lector encontrará muchas más cosas, algunas directa o indirectamente relacionadas con la vida de la Academia; otras, centradas en la historia peruana y española contemporáneas y en la actividad cultural de aquellos tiempos. Resulta de particular interés la postura de Palma ante la posible incorporación de Emilia Pardo Bazán a la Real Academia, violentamente negativa, a pesar de la amistad y del afecto que lo unía a la escritora; la noticia de que la muerte de Marcelino Menéndez Pelayo provocó un duelo de tres días en la Facultad de Letras de San Marcos; sus cálidas palabras para con el joven Ramón Menéndez Pidal, que acababa de ser nombrado Director de la Biblioteca Nacional de Madrid; sus reproches para aquellos académicos de la Española que eran sólo políticos y que nada tenían que aportar a la labor científica de la Corporación. $Y$ aún, entre toda esta información curiosa, también se encontrarán preciosos datos biográficos, arrancados a esa biografía intima y sentimental del Palma casi octogenario, y después.

IV.

Las cartas que aquí se publican -17 en total - forman parte de un conjunto de 27 que entre 1889 y 1919, el mismo año de su muerte, escribiera Ricardo Palma a su amigo Daniel Granada. Las 10 que no transcribo y publico tratan de temas estrictamente personales que no interesan al lector general. Añádase a la colección tres tarjetas postales —fechadas en 1903, 1906 y 1909, respectivamente- con mensajes ocasionales de saludo y felicitación, y una última tarjeta, firmada por su hija, dando noticia de la muerte de su padre.

Todo este material fue celosamente guardado por Daniel Granada hasta su muerte, ocurrida el 6 de septiembre de 1929. Después pasó, junto con su biblioteca y otros bienes, a sus herederos.

Tuve generosísimo acceso a estos textos gracias a la honrosa amistad que me une con D. Daniel Granada Vigil-Escalera, nieto del insigne lexicógrafo gallego-uruguayo. Las puertas de su casa ovetense y las de su biblioteca estuvieron abiertas para mí sin la menor de las restricciones. Siempre recordaré con gratitud aquellas tardes de la calle Santa Susana, en las que en todo momento estuvieron presentes la cordialidad, la colaboración diligente y la admiración compartida hacia un hombre ilustre; para Daniel, su abuelo querido; para mí, un notable lexicógrafo que enriqueció nuestros saberes sobre el español de América de los umbrales del siglo xx. 
Estas cartas que ahora se publican son completamente inéditas 5 . Por ello, sobre todo, confío en que este trabajo ayude, aunque con modestia, al mejor conocimiento de unos hombres y de una época; de unos protagonistas, ejemplares en su dedicación, de la labor académica callada y responsable.

\section{V.}

La publicación de estas cartas, en su mayoría autógrafas, servirá también - asi lo espero- para enriquecer lo poco que sabemos sobre la lengua y la ortografía de Ricardo Palma ${ }^{6}$, sobre su estilo epistolar. La transcripción ha sido completamente respetuosa; nada se ha alterado ni modificado en lo más mínimo. Se trata siempre de una letra clara, bien dibujada, sin grandes problemas de lectura. En las pocas ocasiones en que no me ha sido posible leer con entera certeza, tras mi transcripción coloco un signo de interrogación. Lo que me ha parecido curioso o sorprendente - quizás errores involuntarios, productos de la prisa- lo indico mediante [sic].

Lima, Marzo 8 de 1889.

S. Dn. Daniel Granada. Montevideo.

Mi estimable Señor:

Con su atenta del 5 de febrero he recibido su precioso libro Vocabulario platense [sic]. Aficionado, como soy, a estudios lingüísticos, más que leído he devorado su interesante trabajo. Y tan útil me ha parecido como libro de consulta, que el ejemplar que ha tenido Ud. la amabilidad de dedicarme lo he cedido a la Biblioteca Nacional de la que soy Director. Esto adivinará Vd. que, en buen romance quiere decir que necesito de otro ejemplar para mi modesta librería individual.

$\mathrm{Ha}$ hecho Ud. un concienzudo inventario de provincialismos propios de las repúblicas del Plata. Nosotros usamos en la misma acepción que Ustedes las voces amadrinar, arrope, bagre, balsa, baqueano, bocado, bombacho (y no bombacha), bonaerense, bosta, carbonada, carona, cimarrón, cobijas, conchabar, curaca, chacra, chala, chamuchina, chicote, chango, chata, chicharrón, china, choclo, chusma, chúcaro, churrasco, empacar, galprón, garúa, gringo, guacho, guascar, guayacán, humita, iguana, jagüey, jerga, ladino, llapa, ma-

- Una primera colección de las cartas de Ricardo Palma fue recogida en los dos volúmenes de su Epistolario, Lima, Editorial Cultura Antártica, 1949; con posterioridad, apareció un nuevo libro: Cartas inéditas, Lima, C. Milla Batres, 1964.

- Véase, a este propósito, el impecable estudio de Alberto Escobar, «Tensión, lengua. je y estructura: las Tradiciones peruanas $\%$, Miscellanea di studi ispanici, I, 1962, págs. 33. 89; también el libro de Alessandro Martinengo, Lo stile di Ricardo Palma, «Biblioteca di Cultura», Padova, Liviana Editrice, 1962, pero se refiere a su obra literaria. 
drina, mama y mamita, mandinga por el Diablo, mandioca, manea, maturrango, matrero, mojinete, molle, morocho, mote, nutria, ñato, pajonal, papa y papá, patacón, pateador, pendón, peón, peonada, pericote, picana, piola, pique, pitar y pitada, porongo, poncho, potrero, puna, pulperia, rancho y ranchería, rebencazo y rebenque, repunte (de río), retaco y no retacón, retobar, sancocho por sancochado, sobrecincha, soroche, tamal, tembladera (en la acepción que da U. a tembladeral), totora y totoral, turbonada [,] velorio, vizcacha, yuyo (si bien nunca lo usamos en singular) [,] zanjón y zapallo [.]. Nosotros liamamos cachimba a lo que Ustedes cachimbo. La voz cachimbo la hemos inventado los politiqueros peruanos para bautizar con ese nombre a los soldados de la guardia nacional ó cívica.

Muchas de las voces que apuntadas dejo figuran en la última edición del Diccionario. Yo mandé a la Academia (de que soy correspondiente desde hace doce años) más de cuatrocientas papeletas y de ellas aceptó la Corporación cerca de trescientos peruanismos, o mejor dicho americanismos; pues hay palabras que en idéntico sentido se usan en todas nuestras repúblicas. Estoy seguro de que la Real Academia Española tomará en seria consideración el libro de U., que tan provechosamente vá a servir en la filología castellana.

La Academia peruana, correspondiente de la Española, consta de doce miembros. Se instaló el 30 de Agosto de 1887 y celebra una sesión mensual, precisamente en uno de los salones de la Biblioteca. Dentro de diez días tendremos sesión y mis compañeros hojearán el libro de U. Nos ocupamos en discutir las papeletas que se presentan para, en su oportunidad, enviarlas a la Academia madre.

Tengo la convicción de que, en breve, podré dar a U. el fraternal dictado de Compañero. La Academia de Madrid tiene que acordar a U. la misma distinción que a Magariños y a Zorrilla de San Martin.

No concluiré $\sin$ agradecer la página 245 en, que con muy graciosa y espiritual fabla, trae a colación mi nombre.

Tráteme U. con la llaneza con que yo lo hago desde esta mi primera carta. Las fórmulas de etiqueta epistolar se me estomagan.

Créame muy suyo sincero apreciador y amigo.

\section{Ricardo Palma.}

Salude en mi nombre a Magariños Cervantes y a Zorrilla. El prólogo del primero es digno del cantor de Palmas y Ombúes. Felicítelo de mi parte.

22 de Abril de 1909.

S. D. Daniel Granada.

Madrid.

Muy querido amigo y compafiero:

Gratísima ha sido para mí la lectura de su afectuosa carta del 8 de Marzo. Por ella he sabido que aún perduro en la memoria y en la estimación personal de los compañeros de Academia y hombres de letras con quienes mantuve relaciones hace más de quince años.

He recibido los dos ejemplares del curioso trabajito, que ya me era conocido, de nuestro bondadoso y culto compañero D. Miguel Mir. Salúdelo y 
exprésele mi agradecimiento, y digale que no me olvide cuando publique su anunciado libro Estudios históricos y literarios.

Espero la carta de Carracido que usted me anuncia. Entretanto, digale que el chiquillo de diez años a quien él conoció en Madrid, en mi cuarto de hotel, mi hijo Ricardo, acaba de recibirse de médico, y que por este correo le remite con dedicatoria autógrafa, ejemplar de su tesis. Los libros de Carracido sobre Química le son a Ricardo familiares.

Mi salud, como de anciano, sigue muy quebrantada. Creo haber dicho a usted en mi anterior que, desde hace un año, me está prohibido entintar la pluma literaria.

Corresponda, en mi nombre, el recuerdo de los Señores Director y Secretario de la Academia, y dé un abrazo al compañero don Melchor de Palau, el poeta insigne de la oda al Carbón de piedra.

En todas nuestras repúblicas usamos la palabra porcentaje (el tanto por ciento) en las publicaciones estadísticas. Se escribe, por ejemplo: Al hospital x entraron durante el año 120 tuberculosos de los que murieron 40 , lo que da un porcentaje de... (aquí la cifra que resulte del cálculo. La misma voz se emplea en las estadísticas comerciales). El Diccionario no trae vocablo equivalente. Proponga usted la palabreja á la Academia.

$\mathrm{Y}$ á propósito. Infórmese usted del éxito que ha tenido el verbo presupuestar que yo propuse en 1892. ¿Lo admiten ó se obstinan en rechazarlo? La verdad es que las intransigencias no nos acercan sino nos alejan de la madre patria.

Por supuesto que esta carta no es para [ser] leida en sesión ó junta académica. Puede usted privadamente leerla al padre Mir, á Carracido, á Cortazar, á Palau y á otros pocos.

No hay tiempo para más. Le estrecha la mano su amigo afmo.

\section{Ricardo Palma.}

29 de Julio de 1909.

\section{Señor Daniel Granada.}

Queridísimo compañero y amigo:

Como rayo de sol, en medio de las nieblas anexas á los achaques propios de la vejez, me ha llegado hará tres dias la amable carta de usted fechada el 22 de Junio. Siempre es grato saber que al través de la distancia y de diesisiete años corridos, existen aún en Madrid amigos que como Palau, Carracido y el padre Mir nos recuerdan con afecto.

Desde ayer estamos festejando en toda la nación el $88 .^{\circ}$ aniversario de la Independencia. Esta noche se celebrarán los juegos florales, habiéndose adjudicado el premio, entre las 38 composiciones presentadas, a la titulada Canto á España, que es una magistral producción en alejandrinos del joven don José Gálvez, alumno de jurisprudencia en nuestra Universidad. El jurado lo compusieron don Eugenio Larrabure y Unánsie (vice-presidente de la república y correspondiente de la Española), mi hijo don Clemente, (que hasta hace cinco años fué cónsul del Perú en Barcelona) y el señor Morales, joven catedrático en la facultad de Letras. El laureado poeta es nieto de don José 
Gálvez (Ministro de guerra en 1866 y del cual fuí yo Secretario y muy íntimo amigo) que murió en el combate del Dos de Mayo contra las naves de España que bombardearon el Callao. Como mi salud no me consiente asistir á fiesta nocturna, y el autor supo que yo deseaba conocer su producción, tuvo ayer la amabilidad de visitarme, y, de leermelas. Estoy seguro de que en España será también muy aplaudida.

Me da pena el saber, por los datos que usted se digna comunicarme en su carta, que mientras en América nos esforzamos por acercarnos a la madre patria, la Academia siga obstinada en distanciarse de nosotros en materia de lenguaje. Felizmente el Diccionario es ya letra muerta, pues raro es quien lo consulta, en nuestras repúblicas. Asi, por ejemplo, en nuestra prensa noticiosa empleamos indistintamente estas locuciones: - Se susurra, se rumoreaPara la Academia el susurro es de mejor cepa que el rumor, pues á este le niega verbo. Los americanos somos en esto igualatorios. Adelante con los faroles, y sigamos presuponiendo allende y presupuestando aquende.

Corren vientos de tempestad. Ya sabrá usted que Bolivia ha rechazado el laudo argentino, y que es muy probable que con ese desconocimiento de la fé nacional empeñada surja el para todos ruinoso y lamentable estado de guerra. Posible es que en Octubre ó Noviembre imite el Ecuador el procedimiento boliviano si el laudo que ha de pronunciar el rey de España no les fuera del todo satisfactorio. La altruista doctrina del arbitraje va resultando letra muerta.

Sin tiempo para más estrecha á usted la mano su viejo amigo

\section{Ricardo Palma.}

A última hora. Parece que los Estados Unidos han resuelto intervenir para que la guerra no se declare.

3 de Noviembre de 1909.

Señor Daniel Granada.

Fregenal de la Sierra.

Mi distinguido amigo y compañero:

Ayer recibí su afectuosa del 19 de Septiembre que no quiero perder el Vapor de esta tarde dejándola sin respuesta hasta el de la siguiente semana.

La caída del ministro Maura ha sido motivo de júbilo en el Perú y en las repúblicas vecinas; pero como en política no hay cadáveres no me sorprendería si dentro de un par de años supiese que había resucitado. Por ahora la gran preocupación de Maura ha de ser librarse de los vengadores de Ferrer.

A Dios gracias, en el Perú, no tendremos guerra internacional. La paz con Bolivia se aprobó tranquilamente por el Congreso de Lima el 24 de Octubre, en votación de 128 votos contra 14. El Congreso de $\mathrm{La} \mathrm{Paz}$, en su sesión del 25 de Octubre hizo lo mismo casi por unanimidad, pues solo hubo dos votos por la desaprobación de los tratados. Ojalá que el ministorio [sic] Moret alcance á poner pronto término á la guerra con la morisma del Riff que, según datos de la prensa española cuesta ya más de seis mil víctimas, cifra á la que debe agregarse la incalculable de emigrantes que, despoblando la peninsula, se trasladan a México, Brasil y repúblicas del Plata. 
Me complace la información que me da usted de la buena acogida que han tenido las producciones poéticas del joven Gálvez. Tendré el gusto, cuando venga á visitarme, de hacerle leer los conceptos de la carta de usted.

Dentro de pocas horas empezará sus juntas la Academia de la Historia. Entiendo que, en esa primera junta, dará el Director cuenta de mi queja contra el Marqués de Laurencín.

Con el rechazo de la voz porcentaje no han hecho más nuestros compañeros que vigorizar mi afirmación de que el Diccionario es un cordón sanitario entre España y América.

Mucha salud y ningún sinsabor le desea su viejo compañero y amigo.

Ricardo Palma.

Lima, 16 de diciembre de 1910.

Señor Daniel Granada.

Mi distinguido amigo:

Ante todo lo saludo cordialmente deseándole un año 1911 colmado de ventura.

Paso ahora á avisarle recibo de su afectuosa carta del 3 de Noviembre, sintiendo solo que mis ya crónicos alifafes no me consientan plumear largo como el afecto desearia.

Si usted conoce el folleto del Marqués de Laurencín y lo compara con mi articulo sobre la Ovandina, inserto en la edición barcelonesa de 1894 de mis tradiciones, adquirirá la convicción de que ese bendito Señor no es digno de sacramentos históricos ni de sacramentos literarios.

$\mathrm{La}$ anunciada compilación de documentos relacionados con el autor de la Araucana promete ser publicación muy interesante. No menos valioso ha de ser el estudio crítico sobre Alcázar encomendado á la ilustración y dotes intelectuales de nuestro compañero insigne Rodríguez Marín.

Parece que la Academia se mercantiliza, pues al decidirse á hacer segunda edición de su Diccionario no procede por interés de mejoramiento léxico sino pecuniario. En mi concepto debería la Corporación ir preparando material para que dentro de doce o quince años aparezca la décimo-cuarta edición del Diccionario. En América no nos hace ni pizca de falta.

$\mathrm{La}$ inhibición del real árbitro español en el laudo de nuestro litigio sobre límites con el Ecuador ha producido muy mal efecto entre mis compatriotas. Me abstengo de comentar.

Mi reumatismo, ya crónico, y los demás alifafes anexos á mis ya próximos setentaiocho febreros, no me consienten escribir a usted con la amplitud que, en pasados tiempos, podía hacerlo su viejo amigo y compañero afmo.

\section{Ricardo Palma.}


Lima, 23 de Enero de 1912.

Sr. D. Daniel Granada.

Madrid.

Mi muy distinguido amigo:

Mis dolencias se agravan, y no queriendo dejar sin respuesta su amabilisima carta del 12 de Diciembre, dicto a una de mis hijas estas breves líneas pues el médico me prohibe disertar extensamente.

Compláceme saber que ha regresado usted contento de su veraneo. Que se repita éste por muchos años más.

Me alegro de que Mancei haya cumplido con remitir a usted mi último libro de Apéndice a las Tradiciones y compláceme doblemente el saber que ha sido esa lectura de su agrado.

Mi librero de Madrid me remitió hará dos meses el interesante libro del amigo Rodríguez Marín a quien ruego a usted salude muy carifiosamente en mi nombre. Algo, que no mucho, disculpamos en lo relativo á los primeros ejemplares del Quijote llegados al Perú. Si mi salud funciona y mi tirano Galeno me lo permite, me propongo escribir algunas páginas sobre el precioso tema.

Muy interesante ha de ser la publicación que se propone hacer la Academia sobre Gramática, especialmente si figuran en la obra conceptos de mi inolvidable amigo Benot.

¿Continúa la Academia obstinada en no admitir la voz porcentaje? En el lenguaje parlamentario de las tres repúblicas de Colombia, las del Plata, México, Chile, Bolivia y Perú es de uso constante y uniforme en las discusiones sobre presupuestos, asuntos aduaneros y de estadística. Mal hace la docta corporación obstinándose en rechazar americanismos de empleo generalizado. Raro será el escritor americano que disfrute de algún prestigio en el manejo de la lengua que no haya entintado alguna vez la pluma para escribir porcentaje.

En la primera semana de Febrero completaré 79 años (ya es guarismo!) y entraré Deo volente, en la senda de los octogenarios. Con poco que el vigor me ayude, quizá acometa un nuevo estudio sobre americanismos y neologismos.

Conceda Dios a usted, mi bondadoso y viejo amigo, mucha ventura en el año que comienza y créame siempre suyo afmo. amigo.

\section{Ricardo Palma.}

Sr. D. Daniel Granada.

Madrid.

Queridísimo amigo y compañero:

Casi estoy por agradecer al analfabeto presidente de mi tierra el agravio que se imaginó inferirme al decretar la aceptación de mi renuncia, pues su procedimiento me ha convencido del afecto con que me enaltecen los compañeros todos en la labor literaria, así en mi patria como en el extranjero. Veo, por la afectuosa de usted de 20 de Abril, la para mi muy simpática impresión 
que entre nuestros compañeros de Academia ha producido la velada con que la juventud universitaria y la buena sociedad de mi tierra enaltecieran mi achacosa personalidad.

Llevo ya mes y medio de residencia en este balneario de Miraflores, y asi por la bondad de su clima como por las satisfacciones morales del espíritu mi salud mejora notablemente, a la vez que los ochenta siguen su curso. Desgraciadamente, me siento imposibilitado para la labor literaria, pues la vista disminuye infinito y mi médico me prohibe todo esfuerzo cerebral. Limítome á escuchar las lecturas que me hacen mis hijas y á dictarlas [sic] mi correspondencia, que en los últimos meses ha sido copiosa.

Ya sabía que ha vuelto a ponerse sobre el tapete la candidatura académica de mi amiga doña Emilia, y lo siento. Mi opinión adversa la expuse hidalgamente en el artículo consagrado á juzgar á mi buena amiga en mi librito Recuerdos de España. Mi opinión de entonces perdura.

Satisfago la curiosidad de usted sobre don Pablo Patrón, médico y hombre de letras. Este caballero falleció en Lima á principios de Enero de 1911, casi súbitamente.

Hace unos días que, por cablegrama de prensa, supimos la muerte de nuestro querídisimo Menéndez y Pelayo. La prensa toda de Lima le ha consagrado preciosos artículos y la facultad de Letras en la Universidad se declaró en duelo por tres días. Si la noticia no hubiera llegado en días de agitación popular con motivo de las elecciones para nuevo presidente de la $\mathrm{Re}$ pública, crea usted que en Lima habríamos realizado alguna manifestación más significativa en homenaje á la memoria del ilustre académico que ocupara la vacante dejada por Hartzembuch.

Reiterando á usted mi agradecimiento por las finezas que en su carta me consagra, envía á usted cordialisimo abrazo su viejo compañero y amigo.

\section{Ricardo Palma.}

Miraflores, 29 de Abril de 1912.

Por cablegrama de ayer acabo de informarme del nombramiento de $\mathrm{Me}$ néndez Pidal para la Biblioteca de Madrid. Tiene don Ramón grandes aptitudes para el cargo. En Lima fué un constante rebuscador de antiguos documentos y de libros viejos en la Biblioteca de mi cargo. Con ese motivo tuvimos frecuentes charlas.

Miraflores, 7 de Junio de 1912.

Señor D. Daniel Granada.

Madrid.

Querido compañero y amigo:

Correspondo a su afectuosa del 30 de Abril.

Por cablegrama de los quince últimos días veo que en la España literaria se acaban de realizar dos hechos sensacionales - El primero es el fallecimiento de mi amadísimo amigo Menéndez Pelayo y su reemplazo en la dirección de la Biblioteca con Menéndez Pidal que, como el ilustre muerto, tiene si no iguales, muy aceptables condiciones de bibliógrafo. Entiendo que el nombra- 
miento se ha hecho sin oposición. Sirvase usted poner en sus manos la tarjeta que acompaño.

El otro asunto ruidoso ha sido la declaratoria unánime de la Academia excluyendo al sexo femenino de la distinción académica. Antes de ahora he escrito á usted mi opinión en el asunto, opinión que há más de quince años consignara en mi librejo Recuerdos de España. Lo sorprendente para mí es que mi amiga Doña Emilia no haya tenido patrocinadores en la docta corporación. Cuénteme usted como han pasado estos asuntos. Simple curiosidad de viejo valetudinario.

Mis enfermeras no me consienten seguir escribiendo, pues el médico solo me ha dado licencia para emborronar cartas que no excedan de una carilla. Terrible, tiránica imposición es la del laconismo.

Envía á usted cordial abrazo.

$$
\text { Su amigo afmo. }
$$

Ricardo Palma.

Miraflores (Lima), 26 de Octubre de 1912.

Señor D. Daniel Granada.

Madrid.

Querido amigo y compañero:

Correspondo á su grata del 18 de Setiembre. Mi salud mejora lentamente. Lo que cada día empeora y gana terreno son los ochenta años que completaré dentro de tres meses y medio.

Recibí carta muy afectuosa de Menéndez Pidal en contestación á la que usted le entregó.

El nombramiento de Rodríguez Marín como Bibliotecario, me ha complacido infinito. No nos conocemos personalmente, pero simpatizamos.

De la carta de usted deduzco que no llegó á sus manos un periódico de fecha 31 de Julio, que remití á usted por el vapor del 5 de Agosto, con la descripción de una fiesta que el Congreso de estudiantes de quince repúblicas de América y el Centro Universitario del Perú me dedicaron, para hacerme solemne entrega de un Album de desagravio. La fiesta fue preciosa, y hubo notables discursos de los delegados argentino, brasilero, uruguayo, chileno y boliviano. Fué esa fiesta tan animada como la de la Velada que en Marzo se efectuó en el Teatro y de la que envié á usted periódico descriptivo que felizmente llegó á poder suyo.

Mucho, muchísimo, me han interesado los detalles que usted me comunica sobre la no admisión de doña Emilia en la Academia. Lo que usted no me dice es quiénes fueron los que encabezaron la oposición; sáqueme usted de la curiosidad. Yo fuí y sigo siendo admirador y amigo persona [sic] de la ilustre escritora; pero sigo aferrado en la opinión expresada en mi librejo Recuerdos de España. Han hecho bien, muy bien, nuestros compañeros rechazando la afeminación de la Academia. Una mujer en ella sería el desprestigio y la decadencia y muerte de la docta corporación. Canalejas, Moret, Maura y hasta Echegaray, más que personalidades literarias eran hombre de 
la política y á esta convenía el encumbramiento de la dama. Los demás votos eran hijos del compañerismo entre escritores. El único voto que me ha sorprendido es el de Ramón y Cajal.

Lo del Putumayo y las amenazas de intervención inglesa son por ahora borrasca en un vaso de agua. Ha habido interés mercantil en Londres en crear esta alarma. Es posible que si Colombia insiste en crear nuevo conflicto con el Perú, las cosas se compliquen. No creo en la posibilidad de conflicto grave con ingleses y yankees. - Consérvese con salud y hasta otro día siempre muy de usted afmo.

\section{Ricardo Palma.}

He vuelto á los días de la infancia porque el médico me ha impuesto la prescripción de escribir con pluma de ave.

Miraflores, 2 de Abril de 1914.

Sr. D. Daniel Granada.

Madrid.

Mi muy querido amigo:

Há tres días tuve la satisfacción de recibir su afectuosa del 2 de Marzo.

En puridad de verdad podría decirse que lo acontecido en mi tierra el 4 de Febrero no tuvo caracteres de revolución, pues todos los partidos secundaron la acción del ejército. El presidente destituído era un monomaniaco empeñado en realizar propósitos absurdos. Es ahora cuando surge pequeño conflicto, pues el vicepresidente se obstina en asumir el mando y en que no se haga nueva elección. No correrá sangre, y en Mayo los pueblos eligirán al presidente quien gobernará hasta Setiembre de 1918. La actual Junta de Gobierno, nacida como consecuencia de los sucesos de Febrero procede con mucha discreción. Si, por desgracia, la obstinación acentuada del vice-presidente diera campo para que surgiera conflicto armado distamos mucho de seguir el ejemplo de México.

Veo con tristeza, que nuestra Academia de la Lengua vá muy de capa caída. He recibido el Anuario para 1914 y exceptuando Ricardo León, Jacinto Benavente y Serafín Âlvarez Quintero, dignos del cargo por sus merecimientos literarios, los demás son sólo hombres de la política acaso merecedores de figurar en las otras Academias, pero nunca en la del idioma.

La Academia peruana correspondiente de la española, que constaba de doce miembros está hoy reducida á cinco, Siendo yo su decano pues há más de treinta años que la Academia de Madrid me honró con la distinción académica. La Academia peruana se inaguró en 1885 y hoy de los doce socios tres somos [más que, tachado] octogenarios y enfermos y los dos restantes no se ocupan en literatura. Bien podría, pues, la Academia madre, dar por difunta á ésta su hija. Para colmo de desprestigio han nombrado recientemente académico á don Mariano $H$. Cornejo cuyos méritos en el Perú no son literarios sino políticos y que acaso habría estado bien en la Academia de Jurisprudencia. También nos ha dado el Anuario la sorpresa de ser nombrado correspondiente en el extranjero á Don Pedro José Rada, secretario de la Legación del Perú en Roma, del cual nadie conoce producción literaria. 
Mucho lamento la imposibilidad en que me hayo [sic] de entintar la pluma pues nunca supe dictar ni una carta, y estos asuntos académicos me daría [sic] mucha tela en que cortar.

Sabe usted que es como siempre muy suyo amigo y servidor afectísimo.

$$
\text { Ricardo Palma. }
$$

Miraflores (Lima), Abril 27 de 1915 [sic].

Señor Don Daniel Granada.

San Bernardo, 7.

Mi muy querido amigo y compañero:

La carta de 25 de Febrero la he recibido ayer. Atribuyo el retardo al desbarajuste bélico del presente.

Mucho me ha complacido el que haya llegado á sus manos la labor lingüística del doctor Villar, asi como el haber puesto á usted en relación con el doctor Tello llamado á eclipsar el renombre de aquel. Desde hace tres días se encuentra Tello en un viaje de exploración por Bolivia y el Cuzco. Me complace el que haya sido provechosa para usted la afonetica [sic] de mi finado compatriota.

En la segunda quincena de Enero recibí un ejemplar de la edición catorcena [sic] del Diccionario: fineza que probablemente ha tenido para conmigo nuestro compañero Cotarelo. Hasta ahora no sé que haya en Lima otro ejemplar del Léxico. Son muchos los curiosos que han venido á hojear mi tomo y bastante me he divertido con los comentarios. Eso de que la Academia persista en excluir del habla correcta castellana el verbo presupuestar y otras voces de él derivadas como presupuestioso [?] nombre que damos en el Perú á los empleados públicos que viven de la renta que les asigna el presupuesto ha sido tema para muchas charlas. El verbo dictaminar, tan defendido por mi está de plácemes. Pongo punto a estos temas, pues mi salud no me consiente el envenenarme la sangre.

Como hoy no hay más tema sobre el cual pueda correr la pluma, que el de las feroces matanzas de los beligerantes europeos, pongo punto á esta carta repitiéndome como siempre muy de usted amigo y compafiero afectísimo.

\section{Ricardo Palma.}

Miraflores, 10 de Marzo de 1916.

\section{Sr. Don Daniel Granada.}

Mi muy querido amigo y compañero:

Consecuencia lógica del desbarajuste de correos es el retraso de la correspondencia, pues la carta de usted de 22 de Diciembre llegó á mis manos en la última semana de Febrero.

Del congreso científico que funcionó en Washington son escasas las noticias que la prensa yanqui nos ha transmitido. Espero la llegada del amigo Tello que me traerá amplia información dentro de ocho ó diez días. Tello 
asistió al congreso como delegado del Perú, invitado especialmente por la Institución Carnegie.

He recibido ejemplar del Anuario de la Academia. Más que un centro literario parece nuestra Academia un centro de hombres de política; abundan los exministros.

Muy contento estoy de nuestro secretario don Emilio Cotarelo, pues es asiduo en favorecerme con el envío de las publicaciones académicas. Hágame usted el servicio de hacerle una visita en mi nombre y darle las gracias por sus amabilidades.

De los académicos que conocí y traté en Madrid, ha casi un cuarto de siglo, solo quedan Echegaray, (don José), Peréz Galdós, Carracido, Sollés, Fernandez y González, Menéndez Pidal, Navarro Reverter.

Mi salud cada día más desbarajustada y mi cerebro se resiste á funcionar. Para mi intelectualidad no hay ya goces y tengo que resignarme á oír lecturas. Para colmo de males mi Galeno me tiraniza creando trabas á mi intelectualidad.

Envia á usted cordialísimo abrazo su octogenario amigo.

\section{Ricardo Palma.}

Miraflores, 13 de Octubre de 1916.

Sr. D. Daniel Granada.

Mi muy querido compañero y bondadoso amigo :

Esta mañana tuve la satisfacción de recibir su amable carta de 21 de Agosto que me apresuro á contestar pues el vapor llegó con retraso y zarpa mañana.

Mi salud, desde hace cuatro años, siempre intercadente [sic] y mi cerebro fatigado. Entintar la pluma y borronear papel es para mí obra de romanos.

Un amigo de Barcelona me anuncia remitirme una novela de Fernández y González, en dos gordos volúmenes sobre Cervantes. Probablemente estas dos novelas las traerá el cartero. Tengo para mí que el titulo y el autor son una mixtificación editorial para sacar provecho del centenario.

Mucho, muchísimo me han interesado los informes que usted me da del libro que el mexicano Garza está publicando. Tengo para mi que se trata de un cervantista tan apócrifo como el de Barcelona que le ha levantado un testimonio a Fernández y González.

Julio Tello está ahora en viaje de exploración por las montañas en misión de varios profesores enviados por la Universidad de Harvard y no regresará hasta dentro de un par de meses. Por eso no remito á usted noticias sobre el congreso científico de Washington en el que hizo nuestro amigo brillante papel.

Ya habrá llegado á conocimiento de usted de que estamos en vías de resucitar en Lima á la Academia correspondiente, de la cual solo existimos dos miembros.

Yo propuse á la Academia madre un personal de académicos que ha encontrado así en Madrid como en Lima, muy buena aceptación. Espero pró- 
ximamente carta del secretario Cotarelo, y sí, como lo espero, allana él ciertas pequeñeces, en Enero celebraremos la inauguración solemne. Me aflijirá la imposibilidad física en que me hallo para presenciar la ceremonia.

De los futuros académicos de mi tierra solo dos han sido ministros. Lamento que en España vaya haciéndose la Academia asociación política más que literaria.

Supongo que habrá usted recibido la corona fúnebre que en homenaje á la memoria de Rubén Darío ha publicado el Ateneo de su patria. Es bastante buena.

$\mathrm{Y}$ sin más tela en que cortar pongo punto deseando á usted mucha ventura en el año que estará á las puertas cuando ésta le llegue.

Cordialmente suyo compañero y amigo afmo.

Ricardo Palma.

Miraflores, (Lima), 24 de Abril de 1917.

Sr. D. Daniel Granada.

Queridisimo amigo y compañero:

Ayer recibí amabilísima carta de usted fechada el 20 de Marzo.

Con ochenta y cuatro febreros á cuestas, que completé el 7 de ese mes, las goteras de esta casa vieja paréceme que van en aumento, sobre todo en lo cerebral.

Lo de la Academia correspondiente va siendo enigma sin solución. El 18 de Agosto del año anterior escribí largo y menudo al secretario Cotarelo, proponiéndole diez académicos para completar la docena de los fundadores, pues solo existimos dos; algo más en uno de los diarios de Lima hice publicar la propuesta. Supongo que en el desbarajuste postal de la guerra europea se habrá perdido mi propuesta, si es que no ha surgido alguna intriguilla para estorbar la marcha del asunto. Me llama también la atención el silencio de Cotarelo que ha dejado sin respuesta dos ó tres cartas mías, lo que me maravilla en persona tan cumplida como nuestro secretario.

La salud de nuestro poeta Gálvez mejora, si bien no tanto como mi afecto por él desea.

En el Anuario para 1917 habrá usted leído los nombres de los cuatro académicos peruanos [de la correspondiente, tachado] de los que solo dos pertenecen á la correspondiente.

He recibido el mare-magnum de Toro y Gisbert ó sea la edición española del pequeño Larousse ilustrado.

La condenada guerra europea amenaza envolvernos también á las republiquitas de América, metida como está ya en la danza la patria de Washington. La república de Bolivia que no dispone de agua salada ó de vida marítima acaba de incurrir en la fanfarronada de romper sus relaciones con Alemania. Cuba y Panamá se han aliado á la hermana mayor; tienen ciertas obligaciones, pero Bolivia ... c'est ridicule, como dicen los franceses.

A juzgar por los datos de la prensa, parece que España va en camino de meterse también en la danza. Quiera el buen Dios sacar con bien de este be- 
renjenal bélico al simpático Alfonso XIII y que no solo se libren del conflicto guerrero europeo sino también de la reyerta doméstica.

Lo de la paz entre los beligerantes me parece no imposible, pero sí dificilillo. Ojalá termine pronto este vértigo de horror.

Con la cordialidad de siempre, estrecha á usted la mano, su viejo compañero $y$ amigo.

\section{Ricardo Palma.}

\section{Miraflores (Lima) 1 de Agosto de 1917.}

\section{Sr. D. Daniel Granada.}

Mi muy querido amigo y compañero en letras:

Su carta de 19 de Junio la recibí el 28 de Julio, día de gran animación en mi tierra pues en él se celebra la independencia patria (en 1821) y anualmente se inaugura el congreso. Durante el mes de Julio las familias viven en jolgorio peregne. El 4 de Julio se festeja el gran día de los Estados Unidos [el 5 el de Venezuela] el 9, el de la Argentina -el 14 los franceses echan la casa por la ventana- el 20 los colombianos están de fiesta y el 28 nos toca imitarlos á los peruanos. El 6 de Agosto corresponde á Bolivia, el 10 al Ecuador y el 25 al Uruguay, tocándole á Chile el 18 de Setiembre. No se diría sino que las repúblicas de América viven echando canas al aire. En mi tierra se duplica el alborozo porque en ese día se instalan las cámaras legislativas, con las que no hay ciudadano que no abrigue la pretensión de obtener alguna piltrafilla. Hasta yo confío en que los parlamentarios me aumentarán la renta por contar medio siglo de empleado nacional. Amigo mío, no está la Magdalena para tafetanes ó lo que es lo mismo, no me siento con vigor para borronar sobre literatura ni sobre literatos.

Sin embargo, diré á usted que tan luego como hayan pasado los primeros días de la instalación del congreso que trae soliviantados á los nuevos academicos, hombres de política en su mayoría, empezaré á ocuparme de los detalles relacionados con la ceremonia de inauguración de la Academia correspondiente. Me propongo trabajar para que ésta se realice en la primera quincena de diciembre.

Tenemos de visita en Lima a un conocido literato español Pedro González Blanco que viaja acompañado de su esposa. Se le ha dado un gran banquete al que asistieron seis de los nuevos académicos y muchos periodistas y literatos, entre ellos mi hijo Clemente. ¿Qué informes me da usted sobre las dotes literarias de González Blanco de quien nada he leído? Barrunto que será hombre de política más que de letras. Ya me convenceré si realiza su anunciada visita á este viejo.

Y sin más tema sobre el que dictar a mi secretaria envía á usted un fuerte apretón de manos su amigo y compañero afmo.

\section{Ricardo Palma.}


Miraflores, 27 de Febrero de 1918.

Sr. D. Daniel Granada.

Mi muy querido amigo:

Cada dia es mayor el quebrantamiento de mi salud, y tanto que, sin fuerzas para el trabajo, he tenido que renunciar la dirección de la Academia, renuncia a que, por unanimidad, no asintieron mis compañeros, pero convinieron en declararme director honorario ad perpetuam con el académico ilustre D. Javier Prado y Ugarteche, rector de la Universidad de Lima; para él van a ser el trabajo y las fatigas; decididamente, los ochenta y cinco febreros que llevo a cuestas fuman en pipa.

Paso a contestar a usted la pregunta de su carta de 2 de Diciembre en lo relativo a Rodil. En mis Tradiciones El fraile y la monja del Callao (Tomo I) y El secreto de confesión (Tomo IV) encontrará todo lo relacionado con el padre crucífero o de la Buena Muerte Fray Pedro María luz [sic]. Cuando escribi esas páginas vivía aún mucha gente que conoció y trató al crucífero y era bastante popular la historieta en el Callao cuando se platicaba del sitio y del general. Lo que han dicho a usted los padres camilos acerca de datos por mi proporcionados es exacto y consta en el Secreto de confesión.

Mi opinión es que los padres camilos están en lo cierto. A otra cosa.

Por el vapor siguiente, es decir, antes de quince días recibira usted el $\mathrm{Bo}$ letin de la Academia de Lima, número I, un libro de más de 200 páginas con los detalles de la inauguración. Nos proponemos dar cada cuatro meses un Boletin de la Academia.

El trabajo que tiene usted en preparación sobre las causas de la decadencia de estas academias será aquí leído con vivo interés. Mándemelo en cuanto lo publique.

Mi secretaria se siente fatigada de plumear y yo de dictarla [sic].

Envía a usted cordialísimo abrazo de amigo y compañero afmo.

Ricardo Palma.

Miraflores, 4.IX.918.

Sr. D. Daniel Granada.

Madrid.

Queridísimo amigo y compañero:

Justamente a los sesenta dias de escrita me ha traido un vapor de Panamá la carta de usted de 4 de Julio lo que dado el desbarajuste actual no significa gran retraso. Ya casi me habia acostumbrado a que las cartas, cuando no se perdian definitivamente viajasen tres meses. Calcule Ud. lo gratísima que me habrá sido su nutrida carta.

Paso a satisfacer la curiosidad de Ud. sobre la palabra chalaco. En mis tradiciones he referido que a poco de fundado el puerto del Callao se escondieron en él más de doscientas familias de negros esclavos de la tribu ó raza africana de los chalas. Desde entonces se bautizó (ya más de cuatro siglos) con el nombre de chalaco al habitante ó vecino del Callao.

El artículo de Emilio Cotarelo, secretario de la Academia en el boletín de 
ésta, abunda en pormenores sobre la inauguración de ésta en Lima. Vuelva Ud. a leerlo y estoy seguro de que lo encontrará Ud. minucioso. Supongo que a la fecha habrá Ud. tenido oportunidad para relacionarse con mi compatriota y compañero de Academia, don José Gálvez, que es mozo muy ilustrado y muy caballero que va á Barcelona con el caracter de Consul en busca de la salud. Se lo recomiendo con cariño paternal.

En el tomo IV de la edición ilustrada de mis tradiciones publicadas por la casa Montanery Simón encontrará usted un largo artículo en la página 97, sobre las diversas versiones del origen de los nombres Callao (el primer puerto de la República a dos leguas de Lima) y chalaco (el de sus habitantes ó vecinos). La más autorizada es la que en resumen doy a usted en párrafo anterior.

Le envio otro ejemplar del boletín de la Academia Peruana y agradeceré a usted mucho si puede enviarme las conferencias de la Real Academia Hispanoamericana [de Ciencias y Letras].

Deseándole cabal salud y prosperidad me reitero suyo afmo. amigo y compañero.

Ricardo Palma. 